\title{
LA SIESTA: PERIÓDICO LITERARIO (1886): UN PROYECTO LITERARIO Y LIBERAL INACABADO*
}

\author{
LA SIESTA: PERIÓDICO LITERARIO (I886): \\ a Literary and Liberal Unfinished \\ Project
}

Juanita Albornoz Pelayo ${ }^{1}$

\footnotetext{
* Este artículo hace parte del trabajo que realiza el grupo Discurso y ficción. Colombia y América Latina en el siglo xIx, de la Universidad de los Andes, Colombia, liderado por la profesora Carolina Alzate. La investigación y la escritura fueron desarrollados bajo la tutoría de la profesora Alzate.
}

Cómo citar este artículo: Albornoz Pelayo, J (2020). La Siesta: periódico literario (1886): un proyecto literario y liberal inacabado. Estudios de Literatura Colombiana 46, pp. 95-113. DOI: https://doi.org/10.17533/udea.elc.n46a05

${ }^{1}$ https://orcid.org/0000-0001-9449-5822 j.albornoz10@uniandes.edu.co

Universidad de los Andes, Colombia

Editores: Andrés Vergara Aguirre, Christian Benavides Martínes, Vanessa Zuleta Quintero

Recibido: 15.08 .2019

Aprobado: 21.10.2019

Publicado: 27.12.2019

Copyright: $(2020$ Estudios de Literatura Colombiana. Este es un artículo de acceso abierto distribuido bajo los términos de la Licencia Creative Commons AtribuciónNo comercial - Compartir igual 4.0 Internacional

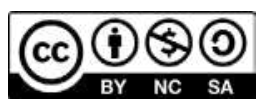

Resumen: este artículo caracteriza La Siesta:periódico literario (1886), delinea algunos puntos clave de su proyecto de formación de comunidad lectora y liberal en la Regeneración (1878-1900) y señala una posible razón de su censura. Sus redactores, Juan de Dios Uribe (1853-1900) y Antonio José Restrepo (1855-1933), fueron literatos y políticos liberales. Aunque los estudios de prensa literaria del siglo XIX colombiano no son nuevos, La Siesta es una publicación poco conocida actualmente. Su contenido literario y político ofrece otras perspectivas para entender la producción textual de la época y enriquece los estudios historiográficos de la literatura nacional.

Palabras clave: La Siesta; prensa literaria; Regeneración; ideología liberal; siglo XIX.

\begin{abstract}
This article characterizes La Siesta:periódico literario (1886), draws up some key points of its formation project as reader and liberal community during the Regeneration (18781900 ) and points out a possible reason of its censorship. The main editors were Juan de Dios Uribe (1853-1900) and Antonio José Restrepo (1855-1933), both men of letters and liberal politicians. Even though the Press Literary Studies of the Colombian $19^{\text {th }}$ Century is not new, La Siesta is not well-known nowadays. Its literary and political content offers other perspectives to understand the textual production of the period and enriches the historiographic studies of the national literature.
\end{abstract}

Keywords: La Siesta; literary press, Regeneration, liberal ideology, $19^{\text {th }}$ Century. 


\section{Presentación}

La inteligencia es el rasgo dominante de nuestro carácter nacional [...]. Elpensamientocomponeydescomponeelmundo(LaSiesta,1886a,p.r).

La Siesta: periódico literario (1886) fue una publicación semanal realizada en la Bogotá de finales del siglo xIx. Sus redactores principales fueron los liberales Juan de Dios Uribe (Andes, Antioquia, 1853-Quito, Ecuador, 1900) y Antonio José Restrepo (Concordia, Antioquia, 1855-Barcelona, España, 1933). Su editor, agente general e impresor fue Fernando Pontón. ${ }^{1}$ En sus artículos se propusieron instruir y orientar al lector del periódico sobre qué leer, cómo hacerlo y sobre cómo debía interactuar o comportarse en su cotidianidad. Si bien el periódico se identificaba a sí mismo como literario, lo cual en la época lo definía como ajeno a la política, esta publicación incluyó en sus reflexiones las críticas al gobierno de Rafael Núñez (Cartagena, 18251894) y a la Iglesia católica, aliada clave de la Regeneración. En este artículo me propongo dilucidar cuestiones como por qué los redactores decidieron caracterizar su periódico como literario luego de la guerra de 1885, por qué el discurso de La Siesta está enfocado en construir e instruir a su lector, qué estrategia utilizaron para llevar a cabo su proyecto, y cuál fue la posible razón de su censura.

Con ello en mente, analizaré los artículos de La Siesta con el fin de entender su discurso y su evolución. En la primera haré una breve introducción a La Siesta, donde intentaré identificar su prospecto y describiré las características de la publicación. La segunda parte está dedicada al proyecto de construcción del lector. Esta instrucción no solo se basó en el ejercicio de la lectura de poesía, sino que también trató de construir y generar una mirada crítica en el lector respecto a su contexto político y social. La tercera y última parte tratará sobre el cierre de La Siesta. Como antesala, en el inicio de la segunda serie, en el número trece, se informa a sus lectores que la publicación fue objeto de crítica por parte de los políticos conservadores Miguel Antonio Caro y Carlos Martínez Silva, lo cual ocasionó una disputa entre los redactores de $\mathrm{La}$

1 Aunque no hay datos del nacimiento y muerte de Fernando Pontón, es posible establecer la ubicación de su imprenta. Según Arturo Escobar Uribe (1964), en El Indio Uribe, o, la lucha por la libertad en el siglo $X I X$, la imprenta a cargo de Fernando Pontón estuvo ubicada en Bogotá en la carrera 6 ${ }^{\mathrm{a}}$, cuadra 11 en el número 266 (p. 182). 
Siesta y los del periódico La Nación: periódico político, literario y noticioso, órgano de los principios de la Regeneración (1885-1890), concluyendo así en la clausura de La Siesta.

\section{La Siesta:periódico literario (1886)}

La Siesta es una publicación semanal que circuló entre el 13 de abril y el 6 de julio de 1886. En el primer número, del 13 de abril de 1886, se indica que Fernando Pontón desempeñaba tres roles dentro del periódico: editor, agente general e impresor. El periódico tenía un tamaño de $30 \mathrm{~cm}$ por $25 \mathrm{~cm}$, impreso en caracteres a dos columnas y cada número está conformado por ocho páginas. Entre sus colaboradores se cuentan Jorge Isaacs, José Asunción Silva, Fidel Cano y Nicolás Pinzón Warlosten, siendo el primero de ellos el más frecuente, quizá por ser tutor de Uribe y amigo cercano de los redactores. Si bien no tuvo una división fija por secciones, publicó con regularidad poesía, ensayos, crítica y, con alguna frecuencia, las secciones "Un mundo bogotano", "Varia" y "Epigramas". El periódico no tenía anuncios publicitarios, y podría inferirse que se financiaba con la venta de los ejemplares, los cuales valían diez centavos cada uno, o con la suscripción por la serie de doce números a solo un peso. A pesar de que circuló y tuvo una organización similar a la de otros periódicos literarios de la época, La Siesta: periódico literario no aparece en los catálogos de prensa literaria colombiana, lo cual conlleva a que no haya un registro escrito de la existencia de esta publicación y a que se confunda con el periódico La Siesta de 1852, dirigido por Rafael Pombo y José María Vergara y Vergara.

La declaración de la intención del periódico aparece en el artículo titulado "Indispensable”, firmado por “Los Redactores” y publicado en su primer número:

Nuestro periódico es un llamamiento apasionado á las letras, por lograr que los ingenios colombianos, después de tan amargos días, se acerquen, se abracen, siquiera en la comunión literaria. El entendimiento humano, profunda é ineludiblemente dividido en todo, pierde las asperezas de la lucha con el filtro de lo bello [...]. En el arte, pues, está la concordia posible; no porque los rumbos sean iguales, ni semejantes los procedimientos, sino porque allí dominan una elevación y una lealtad de ideas extrañas en las faénas comunes ( $L a$ Siesta, i886a, p. I).² 
El prospecto demuestra la conciencia de sus redactores de crear un periódico literario luego de la guerra civil que tuvo lugar entre 1884 y 1885 . El artículo introductorio afirma que la publicación no sigue un pensamiento, doctrina o partido político específico. Los redactores vinculan la literatura con la construcción de pensamiento, mientras que la política, afirman, está unida a las pasiones desmedidas. En este sentido, el periódico se postulaba como un espacio discursivo que no pretendía participar en el debate político entre liberales, conservadores y nacionalistas en sus diferentes tendencias y matices. ${ }^{3}$ Por tal motivo, escriben:

\begin{abstract}
Tratamos de congregar en nuestra modesta hoja á los literatos de todos los partidos. Las opiniones iracundas, que parten en dos á la Nación colombiana, no tienen aquí cabida. Cuestiones de política y de religión son extrañas á nuestra tarea. Todo debate sobre estos puntos es, en el fondo, colérico, y la ira ocupa el puesto que deja vacio la locura. Es el ácido del corazón, impertinente en un periódico literario (La Siesta, 1886a, p. I, énfasis añadido).
\end{abstract}

Azuvia Licón Villalpando (2017), en "Prácticas editoriales en el siglo xıx colombiano: las revistas de Soledad Acosta en el contexto de la prensa", examina el significado que en la segunda mitad del siglo xix tuvo el término prensa literaria. ${ }^{4}$ Según la autora, el vocablo literario nombraba entonces un espacio textual variado que no se corresponde exactamente con lo que hoy entendemos por literatura. Incluía poesía, ensayo, teatro, cuadros de costumbres y novelas, pero sus publicaciones no se reducían a estos géneros. La prensa literaria, afirma, es "un tipo de publicación periódica que busca diferenciarse en contenidos e intenciones de la prensa política y que incluye lo histórico, lo científico y lo artístico" (p. 24). Es el caso de La Siesta, un periódico literario que buscaba conformar una comunidad al margen de la contienda política del momento, permitiendo que autores y lectores coexistieran alrededor de la literatura. En el artículo "Indispensable"

3 Aunque entre 1848 y 1849 la oligarquía intentó crear el Partido Liberal y el Partido Conservador como únicos partidos, en ese momento existían más agrupaciones políticas como el Partido Católico, el Partido Radical y el Partido Independiente. En 1884 Rafael Núñez crea el Partido Nacional para sustentar la Regeneración (Liévano Aguirre, 2002, pp. 363-380).

4 Gustavo A. Bedoya Sánchez (2011), en su artículo "La prensa como objeto de investigación para un estudio histórico de la literatura colombiana”, describe la relación entre la literatura y la prensa literaria como dependiente, pues la prensa, para el autor, es el espacio donde el escritor puede mostrar su producción y someterla a la crítica del público. "Dado lo anterior, una evaluación histórica de la literatura no debe olvidar el análisis de las revistas, los periódicos, los suplementos y los folletines” (p. 92). 
se lee: "No excluimos á nadie; sólo desechamos el género fastidioso. Son suficientes las contrariedades diarias para que uno tenga que aburrirse también leyendo los periódicos literarios. ¡Plaza al talento!”(La Siesta, 1886a, p. 1).

Desde su inicio, pues, La Siesta establece tres puntos importantes que definen su discurso: el desapego de la política (entendida como contienda de partidos), la invitación a participar por medio de la lectura y la escritura en la construcción de una comunidad y, por último, la idea de renovar y ensanchar la producción literaria nacional del momento.

El rasgo de permanecer fuera de la disputa política no es, por supuesto, nuevo, y puede verse en toda la prensa literaria de las décadas anteriores. En El Iris (1866-1868), por mencionar solo uno de los ejemplos, José Joaquín Borda (1886) escribe: "el nuestro será un campo, no oscurecido por las pasiones del partido en donde los amigos de la literatura podrán ensalzar todo lo que es noble i bello" ( $\mathrm{p}$. 1). Así, cuando estas publicaciones afirman su intención de no participar en la discusión política, se presentan como un refugio que permite al lector interesado en la producción literaria tanto disfrutar del arte como producirlo. Sin embargo, en el contexto de la Regeneración y su censura de la prensa, el énfasis de La Siesta en su separación con respecto al debate político podría ser también un intento por desligar el periódico de la ideología política de los redactores, dado que Juan de Dios Uribe y Antonio José Restrepo eran convencidos y reconocidos liberales. De ahí que se proponga, así, como una publicación que, a través del arte, le permite al lector entretenerse, formarse en la literatura y recrear su pensamiento en medio de los avatares de la Regeneración.

Un rasgo que cabe destacar en esta publicación es que en los números de $L a$ Siesta resulta difícil identificar a quiénes corresponde la firma "Los Redactores", pues los artículos que abren los números dos al nueve y once al catorce (ensayos que les corresponden a los redactores) aparecen sin firma. El único nombre que se relaciona con el periódico, como señalé antes, es el de Fernando Pontón. Solo el anuncio del cierre de La Siesta, aparecido en el periódico La Nación (1885-1889) en los números 84 y 86 del 13 y 20 de julio de 1886, especifica cuál fue la participación de Uribe y de Restrepo en la publicación literaria. En el anuncio se lee: 
"LA SIESTA" - Por una disposición del gobierno actual este periódico literario deja de publicarse. No es digno de un ciudadano opinar como sus adversarios. Cuando la Constitución que ahora se dicta en el país esté concluída, tomaremos, de nuevo, parte en los debates de la prensa. Entonces hablaremos de política y literatura, si fuese permitido. - Los Redactores de "La Siesta", Fuan de Dios Uribe, Antonio Fosé Restrepo. - Bogotá 9 de julio de 1886 (La Nación, i886, p. 84).

Restrepo y Uribe, hasta entonces, figuraban solo como colaboradores asiduos de la revista. La ausencia de estos nombres como redactores principales conduce a dos hipótesis. La primera, que la firma de estos literatos liberales podía conducir a la lectura en clave política que querían evitar; el ocultamiento del vínculo entre la publicación y los redactores podría contribuir al propósito manifestado en el prospecto de La Siesta, es decir, a su carácter literario. La segunda hipótesis es que, al no figurar como redactores principales, pretendían eludir ante el régimen la responsabilidad de lo publicado. En efecto, el artículo de apertura del número diez fue el único firmado por Juan de Dios Uribe, y justamente esta entrega es la que se menciona en La Nación antes de que La Siesta perdiera su licencia de publicación. Quizá haya sido este artículo firmado por Uribe el que desató la disputa entre los redactores de La Siesta y La Nación, disputa que mencionaré y que expondré más adelante.

Pese a que las decisiones editoriales en esta publicación, explicadas en el prospecto, se presentan como neutrales, cabe pensar que lo literario, sin ser solo una excusa, quiso servir también para eludir la censura de las ideas liberales de los redactores y conjurar quizá su confrontación con el gobierno regenerador. Si bien el prospecto señala que este periódico pretendía congregar literatos y lectores de todos los partidos políticos, esta voluntad fue puesta en duda por lectores conservadores como Miguel Antonio Caro y Carlos Martínez Silva. ${ }^{5}$ A continuación, expondré cuáles fueron los componentes del proyecto de La Siesta, así como los rasgos que hacen de esta publicación un periódico literario y liberal.

$5 \quad$ Miguel Antonio Caro fue delegado por el Estado de Panamá en el Consejo Nacional de Delegatarios (1886) que redactó la Constitución de 1886. Carlos Martínez Silva también participó en el Consejo y ejerció el papel de secretario. 


\section{El proyecto literario y político de La Siesta}

El compromiso de Juan de Dios Uribe y Antonio José Restrepo con el proyecto liberal y su intención de fundar un periódico literario luego de la guerra de 1885 hace inevitable la relación entre literatura y política. Propongo, pues, que La Siesta fue una publicación que se convirtió en un espacio donde el discurso literario convivió con el político y fueron dependientes uno del otro. El proyecto mismo de instrucción y formación del lector tiene dos grandes pilares, el componente literario y el político, y en ellos se intersecan cuatro líneas claves. La primera es la importancia de los periódicos y de los escritores para el país. La segunda es el deseo de ampliar la historia de la literatura colombiana. La tercera es la necesidad de implementar la crítica para una aproximación más precisa del lector a la literatura. La cuarta es la literatura como formadora de la opinión crítica con respecto al gobierno regenerador y como espacio que conjuga el placer de leer con la conciencia política. En este sentido, La Siesta intentó abarcar la tradición literaria colombiana, el ejercicio de escritura y de lectura, y la crítica literaria y política para definir y modelar un público lector. Dirigido a sus lectores, el periódico pretendía la creación de una comunidad que compartiera costumbres, gustos e ideas a partir de su lectura.

La Siesta, pues, no es solamente un periódico literario, como se lee en su subtítulo, sino, también político. Como señalé antes, Licón Villalpando afirma que el apelativo de prensa literaria, en la época, reúne aquellas publicaciones que abarcaban la ciencia, el arte y la historia y que intentan distinguirse del debate político. Empero, poco a poco, la ideología liberal se reveló como un rasgo importante de las poesías y ensayos que $L a$ Siesta publicó. En efecto, el pensamiento liberal de sus redactores fue clave para llevar a cabo el proyecto de instrucción al lector, pues a través de este se buscó formar opinión en un contexto donde la libertad de expresión estuvo supeditada al parecer del gobierno regenerador. En su capítulo "El discurso como interacción en la sociedad”, Teun A. van Dijk (2008) explica la relación entre ideología y discurso de la siguiente manera:

Las ideologías también establecen vínculos entre el discurso y la sociedad. En un sentido, las ideologías son la contraparte cognitiva del poder. Como en el caso del conocimiento social, las ideologías supervisan cómo los usuarios del lenguaje emplean el discurso en tanto miembros de grupos u organizaciones (dominantes, dominados o competidores), y de ese modo también tratan de realizar los intereses sociales y resolver los conflictos sociales (p. 27). 
El contexto histórico de La Siesta estuvo marcado principalmente por la ideología regeneradora. Los discursos del Gobierno fueron difundidos en los periódicos oficiales, en los artículos de la Constitución de 1886 y por medio de sus representantes más relevantes, Rafael Núñez y Miguel Antonio Caro los más destacados. Por su parte, la creación de La Siesta significó para Uribe y Restrepo la posibilidad de contraponerse a aquella ideología conservadora. Los ideales liberales se manifestaron en el discurso literario del periódico y, con la publicación, llegaron al lector. La difusión de La Siesta alimentaba el deseo de sus creadores de generar en los lectores una respuesta ante el régimen y de fomentar en ellos la opinión y la crítica al contexto social y político. Por ende, el discurso literario fue tan importante como la ideología política liberal: a través de él se intentó crear una comunidad lectora, de gustos literarios afines, interesada en el progreso de la nación, y con un pensamiento liberal independiente y crítico del régimen regenerador.

Sabemos que los periódicos del siglo xIx, incluidos los literarios, participaban de manera activa en su contexto, a pesar de su intento por desligarse de las contiendas políticas. En "Modernity as Ideal and Curse”, Carlos J. Alonso (1998), plantea que en Hispanoamérica la retórica fue especialmente importante en la creación de naciones y en la proyección de estas hacia el progreso, precisando que la retórica no solo alude al texto: "The category 'rhetorical' does not point at all to a purely textual milieu and should be interpreted as alluding to a context that is no less determining and compelling than historical circumstances are conventionally assumed to be" (p. 6). Si entendemos lo retórico tal y como lo explica Alonso, veremos que los discursos y el contexto son inseparables, indistinguibles, y que el uno produce al otro y viceversa. En este sentido, según Alonso, los discursos literarios, y en ellos podríamos incluir la prensa literaria, fueron una respuesta a las circunstancias históricas de las naciones hispanoamericanas y estos contextos se formaban, a su vez, a partir de las producciones textuales de la época. Este es el ambiente en el cual La Siesta delinea su proyecto.

Pasaré, pues, a exponer los cuatro puntos clave de su proyecto de formación de una comunidad de lectores. Propongo que la relación inextricable entre los discursos literario y político que caracteriza al periódico está en el origen de la intención de los redactores de generar un cambio en las costumbres, los hábitos de lectura y en la conciencia política del lector de la época. 
El primer pilar del proyecto de La Siesta abarcó la importancia de los periódicos y los escritores para el país. Los redactores hicieron énfasis en la necesidad de recurrir a los periódicos y a autores olvidados para contribuir al progreso de la nación y a la literatura nacional. En el número doce, Uribe y Restrepo señalan que "cada periódico, á los que nos referimos, es un mosaico en que hombres de mucho talento consignaron los frutos madurados por su inteligencia y por su época" (La Siesta, 1886a, p. 89). ${ }^{6}$ Los redactores muestran a sus lectores que la prensa literaria, como conjunto, es un gran mapa de producciones textuales que contienen las ideas de cada escritor y de cada periodo. El pasado es considerado como el espacio temporal donde el sujeto de 1886 y las generaciones venideras pueden encontrar el talento y la historia nacional. La tarea del público de La Siesta es la de revisitar estos espacios discursivos para deleitarse y rescatar pensamientos y perspectivas que puedan servir para los propósitos del progreso de la nación y el enriquecimiento de la literatura colombiana. Sin embargo, los redactores no tienen una visión optimista de la prensa, debido a que también tiene una connotación negativa: el olvido. Tal perspectiva es, a su vez, un llamado de atención sobre la importancia de La Siesta: el periódico se postula como el guardián de las nuevas producciones intelectuales y de la tradición literaria.

Leyendo curiosos las colecciones de periódicos de toda índole que se han publicado en el país, sufre uno al encontrar entre esas hojas amarillas, rotas muchas, desfiguradas otras, una multitud de artículos que merecen engaste moderno, poesias que no deben estar allí como muertas, y nombres ilustres que el tiempo va borrando á medida que la efímera hoja de papel se convierte en ceniza. Quizá lo que más vale entre nosotros no es lo que está en volúmenes primorosamente encuadernados. [...] Los libros que se leen con agrado por el concurso moderno, entre nosotros, están hechos de artículos dispersos; de poesias arrojadas por abi en los rincones de los periódicos; de disertaciones desparramadas en las gacetas (La Siesta, 1886a, p. 89, énfasis añadido).

Uribe y Restrepo señalan su curiosidad como el origen de la relectura de los periódicos anteriores a La Siesta y contraparte del olvido de las ideas y de los autores. Un rasgo

6 El uso de la palabra "mosaico" para describir la prensa literaria puede interpretarse como una referencia al periódico literario El Mosaico. Esta publicación fue fundada en 1858 por Eugenio Díaz Castro y José María Vergara y Vergara a raíz de las tertulias literarias que se celebraban en Bogotá, con autores de todos los partidos. Circuló entre 1858-1872 con algunas suspensiones y su objetivo fue crear y fortalecer la literatura nacional a través de cuadros de costumbres, poesías y ensayos. 
clave de la postura de los redactores es que reconocen que la literatura no solo está en la prensa literaria, también en las publicaciones de otra índole. Así pues, el lector tiene que ser curioso por naturaleza, pues su conocimiento, pensamiento e ideologías se moldean con lo que está escrito sin importar si es literario o no. Con esta estrategia, los redactores de La Siesta seducen al lector con la promesa de que encontrará en la publicación escritos de otras épocas que no solo lo van a entretener, sino que también lo ayudarán a recuperar ideas olvidadas para su contexto político y social. En este sentido, se tiene conciencia de la función educadora de la literatura. Al respecto, en su obra Ficciones fundacionales, Doris Sommer (2007) señala que "las novelas enseñarían a la población sobre su historia, sus costumbres apenas formuladas, así como sobre ideas y sentimientos modificados por sucesos políticos y sociales que aún no habían sido celebrados" (p. 26). Aunque Sommer analiza las novelas nacionales de América Latina, la escritura en general fue el medio principal por el cual circularon las ideas y, en consecuencia, por el cual se construyeron las naciones.

El segundo elemento del proyecto de formación al lector está íntimamente ligado al primero. Este pilar es la necesidad de ampliar la historia de la literatura colombiana. Cuando Uribe y Restrepo sugieren a sus lectores indagar y releer la prensa del país, su interés también es renovar y enriquecer la tradición literaria de la nación. Según los redactores, "la Historia de la literatura que escribió el señor José María Vergara y Vergara no satisface ni las exigencias más modestas de nuestra civilización" (La Siesta, I886a, p. 89). ${ }^{7}$ Esta premisa indica que la sociedad se ha transformado y que se ha seguido escribiendo, sin tener un registro de la evolución de sus ideas e incluso de su talento. Aunque Vergara y Vergara publicó su estudio en 1867, solo se enfocó en los periodos de la Colonia y la Independencia. Uribe y Restrepo critican aquella decisión del autor porque ignora en su libro la historia reciente de la literatura nacional y la "intelectualidad exuberante de esta tierra" (La Siesta, i 886a, p. 89). Los redactores de La Siesta pretenden renovar y ampliar la historia de acuerdo con las necesidades de su civilización. Se preguntan, también, quién se encargará de llevar a cabo esta tarea y hacen el siguiente llamado: “¿Sería mucho pedir á los ricos que, pues tienen el oro, fomenten la literatura de la patria?”(p. 90). Este interrogante constituye

7 José María Vergara y Vergara (1831-1872) publicó en 1867 su libro Historia de la literatura en Nueva Granada. En este texto se abarca la historia de la literatura de la Nueva Granada desde 1538 hasta 1820. 
un reto a su lector, pues, a partir de él, se infiere que la lectura del periódico no es solo entretenimiento y refugio, sino incentivo a la acción de su público. En su libro Invocación del lector bogotano de finales del siglo XIX, Carmen Elisa Acosta Peñaloza (1993) afirma que "la reacción del lector depende directamente de la intención de la enunciación" (p. 32). Los redactores eran conscientes de que en La Siesta estaban construyendo una comunidad que debía transformar su contexto social y político, así como la literatura de la que surgían las ideas de la nación. Es en este punto donde los redactores proponen que la lectura se convierta en una práctica activa. El papel del lector va más allá de las acciones de comprar el periódico y leer los ensayos y las poesías; el lector es el ciudadano que atiende los llamados del escritor y los pone en práctica en su cotidianidad para contribuir al progreso de Colombia.

El tercer pilar del proyecto de construcción e instrucción del lector es la necesidad de implementar la verdadera crítica literaria. Uribe y Restrepo afirmaban que en Colombia no existía una crítica literaria que se enfocara realmente en la literatura evitando las disputas políticas. Esta carencia de rigor determinaba, según los redactores, el atraso del país, debido a que relacionaban el nivel de progreso de Colombia con la habilidad de escribir crítica. En la cuarta entrega de La Siesta (1886a) sostenían que "la crítica ó arte de juzgar de la bondad, verdad y belleza de las producciones literarias, fundándose en principios de estética ó buen gusto y en las reglas relativas á cada obra [...] es clase de conocimientos poco ó nada cultivada en países atrasados" (p. 29, énfasis añadido). Para estos redactores, la crítica no era solo la facultad de juzgar una obra, sino también el espejo del avance científico de la nación: si no existía la capacidad de evaluar y analizar las ideas que se producían en el país, ¿cómo se pretendía progresar? El señalamiento de los redactores es una estrategia para que el lector entienda que tiene que intervenir en su presente no solo en su contexto político y social, sino también en el intelectual. La realidad que mostraba La Siesta acerca de la crítica literaria en Colombia era prueba de que estaba ocupada por el debate político. En este punto se ve con claridad que para los redactores la literatura está estrechamente vinculada con la política partidista. El inconveniente no es la unión entre literatura y política; lo son más bien las pasiones desmedidas, provocadas por el partidismo, en la producción y la crítica literaria: 
La lucha política mantiene á los escritores colombianos divididos en tantas escuelas y parcialidades como son los partidos, y lo más común es que al juzgar una obra cualquiera de arte no se tengan en mira los excelentes tópicos que señala y sigue el señor Merchán en el prólogo de su libro [Estudios críticos (1886)] sino que se practique en toda su extensión el aforismo usual de las pandillas: á los míos con razón ó sin ella, y viceversa: á tus enemigos contra una esquina. De este modo no hay verdadera crítica, hay sociedades de aplausos mutuos, y denigración permanente. Los conservadores opinan á pie juntillas que ningún liberal vale nada, y los liberales tampoco hacen plena justicia á sus contrarios (La Siesta, 1886a, p. 43).

Finalmente, el cuarto pilar de su proyecto de instrucción y formación es postular la literatura como el discurso en donde es posible manifestar las críticas al gobierno regenerador. Para este punto me enfocaré en una sección en particular: "Un mundo bogotano”. Conformada por crónicas de Bogotá y firmadas por Léo Lespès, ${ }^{8}$ apareció en siete de los catorce números del periódico (en el 2, 3, 4, 5, 6, 7 y 13). El autor de la sección describió la ciudad en tradiciones católicas como la Cuaresma y la Semana Santa, y a través de recorridos en los cuales el lector era su acompañante. Aunque el aspecto religioso sirve para criticar la moral y el poder de la Iglesia en la sociedad regeneradora, me detendré en los paseos que el narrador realiza por la ciudad porque en ellos es donde critica al gobierno regenerador.

La sección "Un mundo bogotano" reconstruye la capital colombiana en recorridos narrados desde la mirada de un cronista. El lector se convierte en un personaje necesario para llevar a cabo el recorrido, pues él es el acompañante del narrador y, por consiguiente, el que ve lo que su guía critica. En la entrega 5 de $L a$ Siesta (1886a) leemos: "Peregrinar por Bogotá! Ya tuvimos ocasión, hace ocho días, de plantar al lector en el centro más concurrido y estratégico, de donde —sí ahí nos ha esperado- vamos á llevarlo á otros puntos" (p. 39). Peregrinar con el cronista y esperarlo hasta el próximo número son acciones que resaltan el carácter activo de la lectura del periódico. Si el lector accede a esperar al cronista y a continuar el recorrido

8 En La Siesta se define la sección “Un mundo bogotano” como crónicas de Bogotá. La firma de estos artículos es la de Léo Lespès, seudónimo del reconocido periodista francés Antoine Joseph Napoléon Lespés (Bouchain, 1815-París, 1875). Como se ve, la fecha de fundación y circulación de La Siesta (1886) no coincide con las de la vida del cronista francés. No he podido establecer quién era el escritor que utilizaba ese seudónimo para escribir la sección; quizá Antonio José Restrepo haya tomado prestado el nombre, pues de los redactores principales, fue nombrado cónsul de Havre en 1884 y permaneció en Francia hasta el fin de la guerra de 1885 en Colombia (Uribe, 2013, p. 162). 
que le propone, permite que este último lo lleve por lugares de su elección y que le exponga sus juicios sobre la sociedad y el Gobierno, modo en el que el autor revela la ciudad al lector.

Realizado el pacto entre el cronista y el lector, se procede a visitar espacios que no suelen entrar dentro de la representación usual de la ciudad. Léo Lespès se desplaza a los lugares en construcción y transformación que tienen el potencial de llegar a ser hermosos y luego transita por aquellos que contradicen el ideal de progreso. Así, cuando el cronista decide incluir en su recorrido estos espacios realiza una cartografía urbana que evidencia que la ciudad y el imaginario de nación comprende no solo a las clases sociales altas o medias, sino también a los indigentes, los locos o los reos. Así pues, el paseo puede incluir el parque Centenario o Chapinero, pero también el asilo de enfermos mentales o el Panóptico. La población se define por los lugares que habita, $\mathrm{y}$, por ende, las visiones del progreso tienen que incluirlos en sus proyectos.

Visitar aquellos lugares que no mueven al orgullo patriótico es, al mismo tiempo, la estrategia del cronista de presentarle a su acompañante su crítica a la injusticia de la sociedad y su Gobierno. El Panóptico es el espacio que Lespès escoge para dar a conocer su opinión. Lo presenta como un proyecto inacabado por el "pasado régimen, por el Gobierno del antiguo Estado de Cundinamarca, que se propuso tener en su capital un Establecimiento penitenciario modelo" (La Siesta, 1886a, p. 40). Esta presentación muestra que hubo un proyecto penitenciario previo de la puesta en marcha de la Regeneración, el cual pretendía dar ejemplo en la nación. La crítica del cronista denuncia que la intención del régimen anterior no se ha llevado a cabo porque en su momento de escritura

[h]ay reos - y qué reos! - que mandan poner á los otros el grillete al pié, mientras ellos ostentan ufanos las cadenas de oro con que mantienen la adulación sumisa á sus plantas. Consolémonos con que esos vivan presos en su conciencia, que es siquiera cárcel de imposible fuga, y pena sin humano indulto (p. 40).

¿Quiénes son los presos? ¿Quiénes ostentan las cadenas de oro? Sin mencionar nombres, la crítica está ahí y el lector es el encargado de asociar el comentario con los personajes que gobiernan en su momento histórico. Una vez más, la escritura invita a 
un proceso de análisis del cual el lector debe sacar conclusiones. Así pues, vemos que un paseo por la ciudad es ocasión para criticar y atacar al régimen regenerador. La escritura y la lectura se convierten, entonces, en prácticas políticas.

\section{El fin de un proyecto literario liberal}

Durante la Regeneración (1878-1900) el control sobre el pensamiento, la palabra escrita y la imprenta fue una estrategia política para procurar el orden de la nación. El artículo 42 de la Constitución de 1886 estableció: "La prensa es libre en tiempo de paz, pero responsable, con arreglo a las leyes, cuando atente a la honra de las personas, al orden social, y la tranquilidad pública" (Ramírez Cleves, 2009, pp. 170-171). Esta disposición fue complementada con el Literal $\mathrm{K}$ de las disposiciones constitucionales transitorias. ${ }^{9}$ Ante el avance de periódicos de ideologías y doctrinas diferentes a la Regeneración, toma forma el Decreto 151 de 1888, el cual le otorgó al Gobierno la potestad de regular la prensa y censurarla.

El 6 de julio de 1886 fue la última fecha en la que La Siesta se imprimió y el proyecto que Uribe y Restrepo emprendieron llegó a su fin, luego de que a los redactores se les quitara la licencia de publicación. Sin embargo, desde el número trece de La Siesta se anunciaba la clausura del periódico. En la penúltima entrega los redactores usaron sus páginas para denunciar ante sus lectores que Miguel Antonio Caro y Carlos Martínez Silva, periodistas de La Nación, habían hecho que el Gobierno les retirara el permiso para publicar:

Se quiso, con pertinaz empeño, que el Gobierno, ya que había tenido á bien darnos permiso para publicar "La Siesta" retirara la licencia, como si, por una parte, ese fuera en algún modo de contestar á los escritores, y, por otra, como si el Gobierno tuviera alguna queja de nuestra hoja, ó fuera decoroso para la República que hiciese solidaria la causa del orden con la causa personal de los señores Martínez Silva y Caro. Estas líneas y las demás que contiene el número presente se hicieron indispensables, á pesar nuéstro; pero no iremos más lejos, á no ser que los señores Redactores de La Nación recaben del señor Secretario de Guerra, ó de quien corresponda, una orden auténtica en virtud de la cual podamos escribir sin ninguna cortapisa (La Siesta, 1886b, p. 98).

9 En el número ocho del 1 de junio de 1886 La Siesta publica el mismo texto, pero bajo el número 39 y el Literal K lo señala como Literal G. 
Los redactores de La Siesta pusieron en duda la independencia del gobierno regenerador e hicieron hincapié en la influencia de La Nación en sus decisiones. Estos liberales entendieron que la ley y su aplicación se reducía al pensamiento y resolución de Martínez Silva y Caro.

La Siesta y La Nación fueron campos de batalla política. Las publicaciones funcionaron, entonces, como lugares discursivos cuyos periodistas, opositores declarados de las ideologías políticas del otro, podían elaborar sus críticas. Los discursos literario y político eran los escenarios donde se manifestaban las opiniones que respondían a las provocaciones de sus adversarios y, en medio de estas confrontaciones ideológicas, el lector se desempeñaba como el árbitro del conflicto. En el artículo "Zancadilla" de La Siesta, del 20 de junio de 1886, número trece de la segunda serie, los redactores informan a sus lectores, a los únicos a los que podían acudir, del ataque de Martínez Silva. Uribe y Restrepo abren el texto de la siguiente manera: “Otra vez 'La Nación', y en ella no yá el señor Caro, sino el señor Martínez Silva, acomete á nuestro periódico. Hacemos entre los dos una diferencia, y es que el primero sabe muchas veces lo que dice, y el segundo dice siempre lo que ha oído..." (La Siesta, 1886b, p. 97). La locución "otra vez" deja ver que el cuestionamiento entre los redactores de los periódicos era constante. La escritura se convierte en un arma defensiva y es en el discurso de Uribe y Restrepo donde se intenta persuadir al lector de que Caro y Martínez Silva no son superiores a sus opositores ni mucho menos inmunes a la crítica. La comparación que se plantea entre estos dos regeneradores apunta a la imagen de intelectuales que ostentaban en la época, poniendo así en tela de juicio la autoridad de Caro y Martínez Silva de formar opinión pública.

Quizá el ejemplo más relevante del uso del discurso literario como medio para expresar las críticas a la Regeneración y sus representantes es el número diez del 10 de junio de 1886. El número en cuestión es un homenaje a Antonio Ricaurte en el centenario de su nacimiento. En esta entrega, el artículo inicial se titula "Heroico" y está firmado por Juan de Dios Uribe. Llama la atención que este texto sea el único ensayo que incluye la firma del redactor y que el tópico del héroe sea el motivo para criticar entre líneas la gestión del proyecto de la Regeneración de Núñez. La figura del héroe nacional, atribuida a Ricaurte, encarna la libertad y la posibilidad de que el pueblo pueda manifestarse contra las medidas del gobierno de turno. En este 
artículo se ve con claridad que el periodista toma el discurso literario para expresar su pensamiento crítico y espera que su lector reaccione con un cambio en su visión frente a su contexto o incluso con un alzamiento:

\begin{abstract}
El sacrificio por el bien, que causa asombro, es lo que constituye el heroismo; nó la inmolación ruidosa por una idea, cuando ella es injusta. De suerte que el dictado de heróico es una merced de la libertad, que pocas veces dispensó con más largueza que en San Mateo. La justicia de la Independencia, que han querido volver litigiosa algunos vasallos oficiosos de la Península en nuestra patria, es innegable, así como la oportunidad del alzamiento: siempre es bien venido el derecho (La Siesta, 1886a, p. 73, énfasis añadido).
\end{abstract}

Igualmente, en el número diez figuran varios poemas, entre los cuales se destaca "La Libertad" de Antonio José Restrepo. De acuerdo con Juan de Dios Uribe (2013), en el Prólogo a las poesías originales y traducciones poéticas de Antonio José Restrepo de 1898, "con motivo del primer centenario del nacimiento de Ricaurte [...] [Restrepo] enumera lo que taladra la libertad [...] en versos que se disparan rectamente sobre el dictador" (p. 168). Aunque esta declaración fue escrita doce años después de censurada La Siesta, es oportuno rescatarla. Uribe confirma que el discurso literario tuvo un papel protagonista a la hora de ejercer el periodismo: la crítica podía ejercerse desde la estética, desde la poesía. Así pues, el propósito de lo bello de las ideas y del pensamiento va más allá del deleite. Lo bello sirve para molestar al poder. Para ilustrar esto, transcribo una de las estrofas más dicientes y significativas del poema "La Libertad" de Antonio José Restrepo: "Libertad que amedranta / del tirano la torva fantasía / que de sus ojos cóncavos ahuyenta / la clara luz del día” (La Siesta, 1886a, p. 74).

El periódico de Restrepo y Uribe fue recibido por una parte de la audiencia como meramente político, lo que significó que el ejercicio crítico de los redactores fuera visto como una sublevación desde el discurso y no como un ejercicio de creación literaria y de expresión de pensamiento. Lamentablemente es imposible consultar los artículos de La Nación previos al mes de julio de $1886 ;{ }^{10}$ sin embargo, me permito

10 No hay en la Biblioteca Nacional de Colombia una copia en microfilm del primer semestre de 1886 de $L a$ Nación; el único ejemplar impreso del periódico está en mal estado y, por ello, es inaccesible a los investigadores. Lamentablemente, no he podido localizar registros en otras bibliotecas. 
transcribir algunas líneas de La Siesta que son la respuesta a la crítica de Martínez Silva, en los últimos días del periódico, para que el lector tenga una idea, siquiera parcial, sobre el contrapunto entre los periodistas de ambos periódicos:

\begin{abstract}
En otro artículo de "La Nación" se nos niega el derecho para saludar á Ricaurte en su sacrificio, por cuanto tenemos ideas filosóficas y morales distintas de las del señor Carlos Martínez Silva. [...] Sería porque las ideas monárquicas del señor Caro no se compadecían bien con las ideas republicanas de Ricaurte; y sería porque las ideas ascetas del señor Martínez Silva no estaban de acuerdo con las ideas despreocupadas del héroe de San Mateo, un tanto hereje, según lo rezan los biógrafos (La Siesta, 1886b, p. 97).
\end{abstract}

Si bien Juan de Dios Uribe afirmó en el prólogo de 1898 que "el objeto de la publicación [ $\mathrm{La}$ Siesta] era, so pretexto literario, escribir política roja” (Uribe, 2013, p. 167), es pertinente destacar que la literatura y la conformación de una comunidad lectora fue importante en el periódico, pues a través de ellas pudieron participar en el proyecto de creación de nación. El discurso literario se entretejió con la ideología política liberal, y no cabe duda de que a través de la estética se intentó molestar al poder. Empero, el lector regenerador privilegió la ideología liberal con respecto el carácter literario del periódico, y ello llevó al prematuro cierre de La Siesta.

¿Qué acciones de Uribe y Restrepo condujeron a tomar la determinación de clausurar La Siesta? En primer lugar, pensar distinto. El mérito de los redactores del periódico fue examinar de manera crítica su contexto, es decir, pensar de manera independiente a pesar de la represión del pensamiento. En segundo lugar, escribir. Una virtud, propia de ellos, fue utilizar el discurso literario para desarrollar su proyecto liberal, considerado subversivo y amenazador para el régimen regenerador. La escritura de lo que hoy en día entendemos como literario, es decir, poesía, ensayo, novelas, entre otros géneros, fue para ellos evidentemente política, como lo es para nosotros hoy. En tercer lugar, crear una comunidad lectora. Atreverse a conformar una comunidad en torno a la preservación de la literatura y del pensamiento liberal resultó ser una acción peligrosa para el régimen, debido a que buscó generar en el público la necesidad de debatir su contexto y expresar sus ideas con libertad. 
A pesar de que esta investigación solo se basó en el periódico de Uribe y Restrepo, fue posible establecer algunos elementos clave en la intención de los redactores de formar una comunidad lectora y de ideología afín. Con mi interpretación de La Siesta espero que los lectores de este artículo se animen a revisitar sus páginas para entender la producción de prensa literaria en la Regeneración desde una mirada liberal. Sin embargo, La Siesta es solo un periódico más de los muchos que nacieron y murieron prematuramente. Para entender nuestra historia literaria nacional es necesario mirar y visibilizar estas producciones periódicas decimonónicas. Los investigadores tenemos la tarea de rescatar las ideas que se difundieron en estas publicaciones y compartirlas no solo a la academia, sino también a la sociedad.

\section{Referencias bibliográficas}

Acosta Peñaloza, C. E. (1993). Invocación del lector bogotano de finales del siglo XIX. Bogotá: Instituto Caro y Cuervo.

Alonso, C. J. (1998). Modernity as Ideal and Curse. In The Burden of Modernity: The Rhetoric of Cultural Discourse in Spanish America (pp. 3-49). New York: Oxford University Press.

Bedoya Sánchez, G. A. (2011). La prensa como objeto de investigación para un estudio histórico de la literatura colombiana. Balance historiográfico y establecimiento del corpus. Estudios de Literatura Colombiana 28. Recuperado de https://bit.ly/35n082V [08.04.19].

Borda, J. J. (1886). El Iris. El Iris. Periódico literario, dedicado al bello sexo. Bogotá. Trim. I, núm. 1. Escobar Uribe, A. (1964). El Indio Uribe, o, la lucha por la libertad en el siglo XIX. Bogotá: Editorial y Tipografía Hispana.

La Nación (1886). La Nación: periódico politico, literario y noticioso, órgano de los principios de la regeneración. (1885-1890). Bogotá: Imprenta de "La Luz".

La Siesta. (1886a). La Siesta:periódico literario I (1-12). Bogotá: Imprenta a cargo de Fernando Pontón.

La Siesta. (1886b). La Siesta: periódico literario II (13-14). Bogotá: Imprenta a cargo de Fernando Pontón.

Licón Villalpando, A. (2017). Prácticas editoriales en el siglo xıx colombiano: las revistas de Soledad Acosta en el contexto de la prensa. Capítulo uno. En Leer la prensa. Edición, autoría y público lector en Soledad Acosta de Samper (tesis doctoral) (pp. 12-96). Bogotá: Universidad de los Andes. 
Liévano Aguirre, I. (2002). Los partidos tradicionales contra el nacionalismo. En Rafael Núñez (pp. 363-380). Bogotá: Intermedio Editores.

Ramírez Cleves, G. A. (2009). Los artículos sobre libertad de imprenta de Bentham y Miguel Antonio Caro: divergencias y eventuales correspondencias. Revista Derecho Del Estado 22, pp. 159-182. Recuperado de https://bit.ly/2Eh2y7v [20.02.2019].

Sommer, D. (2007). Romance irresistible. En Ficciones fundacionales. Las novelas nacionales de América Latina (pp.17-46). Bogotá: Fondo de Cultura Económica.

Uribe, J. de D. (2013). Obras completas de Juan de Dios Uribe. Parte II. Medellín: Fondo Editorial ITM.

Van Dijk, T. A. (2008). El discurso como interacción en la sociedad. En T. A. van Dijk (Ed). El discurso como interacción social (pp. 19-66). Barcelona: Editorial Gedisa, S.A. 